\title{
Design of Lighting System for Substation Area 13 LPG Arun With Lumen Calculation Method
}

\author{
Enda Wista Sinuraya*, Bambang Winardi, Agung Nugroho, \\ Imam Santoso, Denis
}

\author{
Department of Electrical Engineering, Diponegoro University, Semarang Indonesia \\ *Corresponding author details: Enda Wista Sinuraya; sinurayaenda@gmail.com
}

\begin{abstract}
Lighting is one of the important factors in designing space to support user comfort and safety. To carry out all activities that are in a room, an adequate lighting intensity is needed, namely in accordance with predetermined lighting standards, so in designing the lighting of a room it must be carried out with full accuracy, among others in terms of lamp selection, calculation of the number of lamps needed and setting the condition of the lights in illuminating the room. LPG Arun is one of the projects being worked on by PT. Engineering. One of the stages of the process is to design the intensity level of artificial lighting in the Electrical room building. In designing artificial lighting, DIALux 4.10 software is used. In this simulation, a more accurate design result is obtained because it can simulate in 3D. Also obtained the value of the intensity of light and the number of lights needed in the lighting. In this design the results are obtained where the artificial lighting design in each room is in accordance with the owner's request standards.
\end{abstract}

Keywords: electrical room; DIALux 4.10; illumination and electrical installation

\section{INTRODUCTION}

Lighting is one of the important factors in designing space to support user comfort and safety. A room with a good lighting system can support the activities carried out in it and also as a safety factor for workers in the event of an emergency such as lighting leading to the exit (Escape Plan). To carry out all activities that are in a room, an adequate lighting intensity is needed, namely in accordance with predetermined lighting standards, so in designing the lighting of a room it must be carried out with full accuracy, among others in terms of lamp selection, calculation of the number of lamps needed and setting the condition of the lights in illuminating the room.
LPG Arun is one of the projects being worked on by PT. Engineering. One of the stages of the process is to design the intensity level of artificial lighting in the Electrical room building.

\section{RESEARCH METHOD}

(1) Lumen Method

The lumen method is used to calculate the illumination which represents the average illumination at all points on the indoor work plane (Indoor).

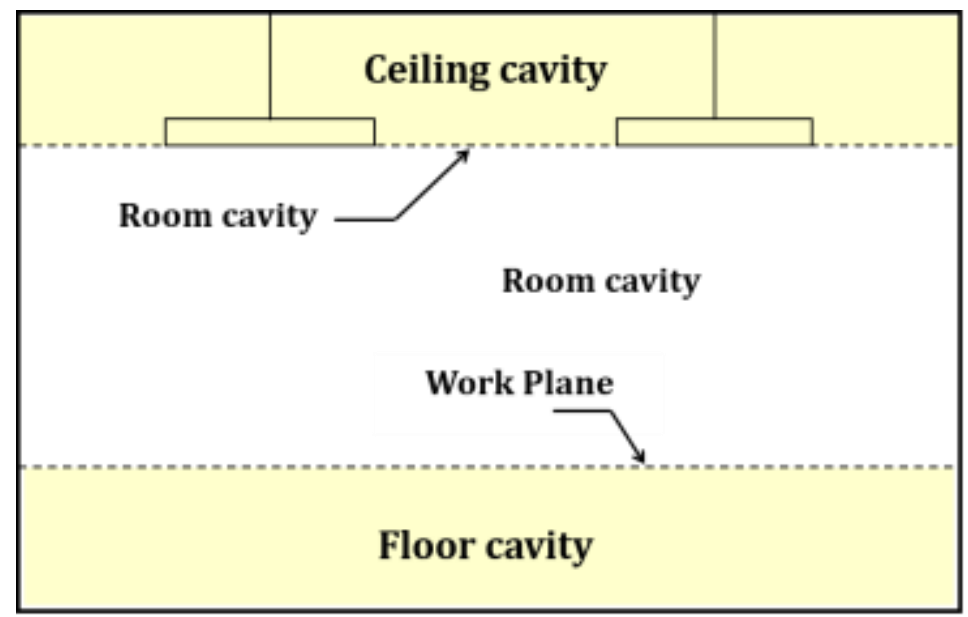

FIGURE 1: Determination of the Room Cavity 


$$
R C R=\frac{5 \times h_{R C} \times(L+W)}{L \times W}
$$

Where:

RCR = Room Cavity Ratio.

$\mathrm{L} \quad=$ Length of Room (m).

$\mathrm{W}=$ Width of Room (m).

$\mathrm{h}_{\mathrm{RC}}=$ Mounting height of lamp above working plan (m).

Step 1: Determine the Room Cavity Ratio (RCR) Step 2: Determine the Effective Reflection from the ceiling, walls, and floor ( $\rho$ )

Reflection factor or reflection factor is the value of the effective reflection of an object, both from the ceiling (ceiling), walls (wall), and floor (floor). Usually the value of the effective reflection depends on the material and color contained in the object. The following table reflects the reflection factor (referring to the IES Hand Book).

While the value of the reflection factor commonly used in the calculation of indoor illumination (Indoor) is assumed as follows:
(a) Ceiling $=80 \%$
(b) Wall $=50 \%$
(c) Floor $=20 \%$

\section{Step 3: Determine the Coefficient of Utilization} (CU)

The value of the reflection factor greatly affects the value of the Coefficient of Utilization (CU), where the value of the Coefficient of Utilization (CU) can be determined using the Coefficient of Utilization (CU) table.
Step 4: Determine the Lamp Lumens (LL) value from the catalog

Step 5: Determine the Minimum Number of Lights (Nt)

$$
N_{t}=\frac{E \times A}{C U \times L L \times M F}
$$

Where:

$$
\begin{aligned}
& \mathrm{N}_{\mathrm{t}}=\text { Number of lights needed } \\
& \mathrm{CU}=\text { Coefficient of Utilization (CU) } \\
& \mathrm{LL}=\text { Lumens of the lamp (lumen) } \\
& \mathrm{E} \quad=\text { Required lux value (lux) } \\
& \mathrm{A} \quad=\text { Surface area }\left(\mathrm{m}^{2}\right) \\
& \mathrm{MF}=\text { Maintenance Factor/Light Loss Factor }
\end{aligned}
$$

Step 6: Rounding the Number of Lamps (Nr). Step 7: Determine the Average Illumination Level Achieved (Eav).

$$
E_{a v}=\frac{E \times N_{r}}{N_{t}}
$$

Where:

$\mathrm{E}_{\mathrm{av}}=$ Average Illumination Level Achieved (lux)

$\mathrm{E}$ = Initial Illumination Level Requested (lux)

$\mathrm{N}_{\mathrm{t}}=$ Minimum Number of Lights

$\mathrm{N}_{\mathrm{r}}=$ Rounding Number of Lamps

\section{(2) Design of Indoor Area Substation 13}

The design of the Indoor Area Substation 13 LPG Arun building to be built is $33.75 \mathrm{~m} \times 8 \mathrm{~m}$ and is divided into 10 rooms, including:

TABLE 1: Dimensional Data for Each Room

\begin{tabular}{|c|c|c|c|c|}
\hline Building & Room & Room Size & $\begin{array}{c}\text { Height Build } \\
\text { Room }\end{array}$ & $\begin{array}{c}\text { Installation of } \\
\text { lights }\end{array}$ \\
\hline $\begin{array}{c}\text { Indoor Area } \\
\text { Substation 13 }\end{array}$ & Panel room & $33,75 \mathrm{~m} \mathrm{x} \mathrm{8m}$ & $4 \mathrm{~m}$ & $3 \mathrm{~m}$ \\
\cline { 2 - 5 } & Battery room & $2,85 \mathrm{~m} \times 2,35 \mathrm{~m}$ & $4 \mathrm{~m}$ & $3 \mathrm{~m}$ \\
\hline
\end{tabular}

The following is a room plan in CAD form

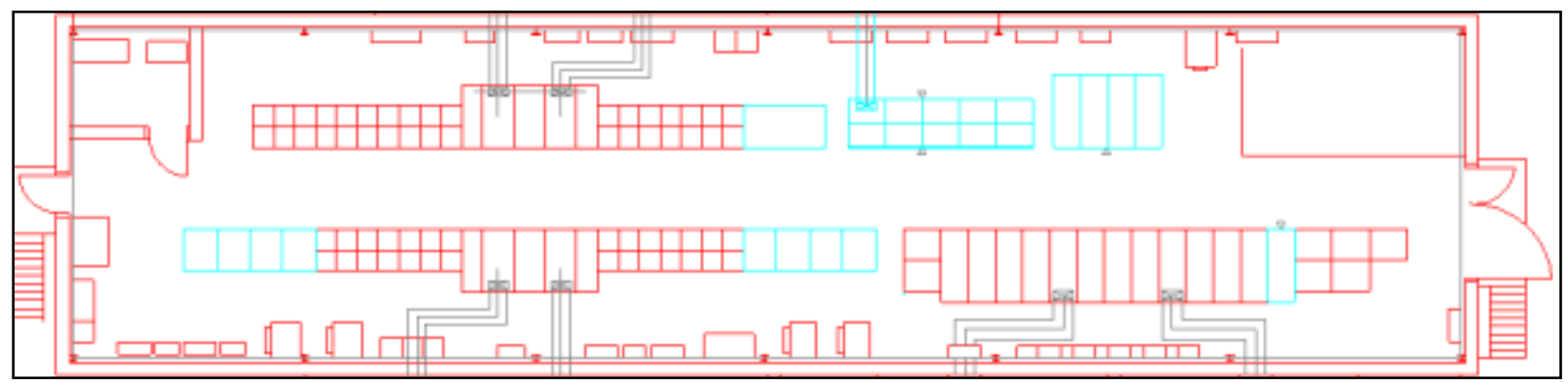

FIGURE 2: Layout of Indoor Area Substation 13 LPG Arun

In the design of the building there is 1 panel room with dimensions of $33.75 \mathrm{~m} \times 8 \mathrm{~m} \mathrm{x} 4 \mathrm{~m}$ and 1 battery room with dimensions of $2.85 \mathrm{~m} \times 2.35 \mathrm{~m} \times 4 \mathrm{~m}$. 


\section{(3) Installation Specifications}

TABLE 2: Lighting Level Requirements

\begin{tabular}{|c|c|c|c|c|}
\hline Room & Mounting Height & \multicolumn{2}{|c|}{ Illumination Level (Lux) } & Measuring Point (Work Plane) \\
\hline \multirow{3}{*}{ Panel room } & \multirow{3}{*}{$3 \mathrm{~m}$} & $\mathrm{~N}$ & 300 & \multirow{3}{*}{ floor } \\
\hline & & E & 50 & \\
\hline & & EB & 10 & \\
\hline \multirow{3}{*}{$\begin{array}{l}\text { Battery } \\
\text { room }\end{array}$} & \multirow{3}{*}{$3 \mathrm{~m}$} & $\mathrm{~N}$ & 300 & \multirow{3}{*}{ floor } \\
\hline & & $E$ & 100 & \\
\hline & & EB & 50 & \\
\hline
\end{tabular}

According to the data in table 2 . Lux requirements in each room include:

(a) Panel room: 300 Lux (normal condition), 50 lux (emergency condition), and 10 lux (emergency battery back-up) with the measurement point on the floor

(b) Battery room: 300 Lux (normal condition) and 100 lux (emergency condition), and 50 lux (emergency battery back-up) with the measurement point on the floor.

\section{Design and Simulation Results}

- Simulation Design Stage

1. Import the Substation 13 layout in the form of data in .DWG format then determine the dimensions of each room according to what has been determined, including:

That is by editing Room Geometry, creating room dimensions using polygons and adjusting the height of the room

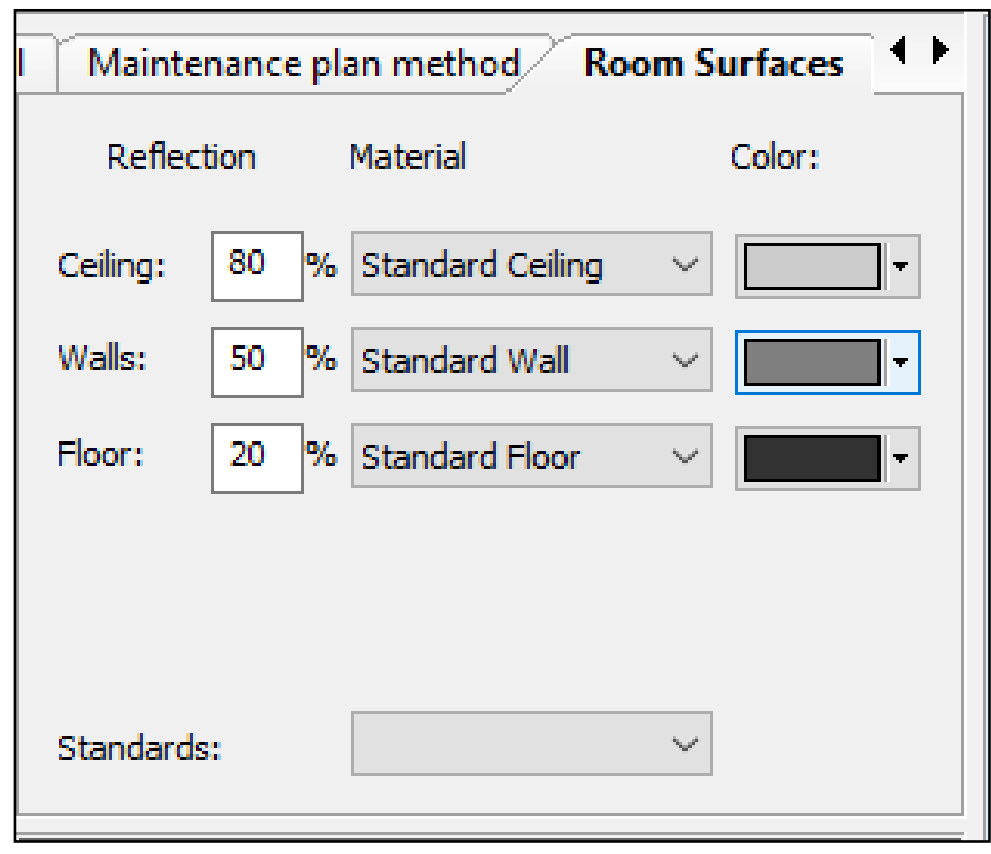

FIGURE 3: Determination of Reflection Factor Value

a. Determine the workplane value

Workplane is the point of height of the work or it can also be called the measurement point of the lighting. The height of the workplane can vary depending on the needs and characteristics of the room. In this simulation, a workplane height of 0 meters is used from the floor.

\section{b. Designing a room in three dimensions (3D)}

One of the advantages of the Dialux software is that it can simulate 3D shapes, so that more accurate lighting results are obtained. In the Panel room and Battery room, there are panels and other supporting components in the room.
The way to do three-dimensional simulation is to use object features using standard elements, and then adjust the geometry of the dimensions that have been determined from the data and their placement. After making all the components in the room, both the Panel room and the Battery room. Then the results will be obtained three-dimensional appearance as follows:

\section{Lamp Settings}

The type of lamp that will be used is a fluorescent lamp (FL) or TL lamp. Selection of lamps based on the catalog that is already installed and available. In this simulation, the Philips TTX080 361 2xTL-D36W HFE + GMX080 R lamp will be used. 


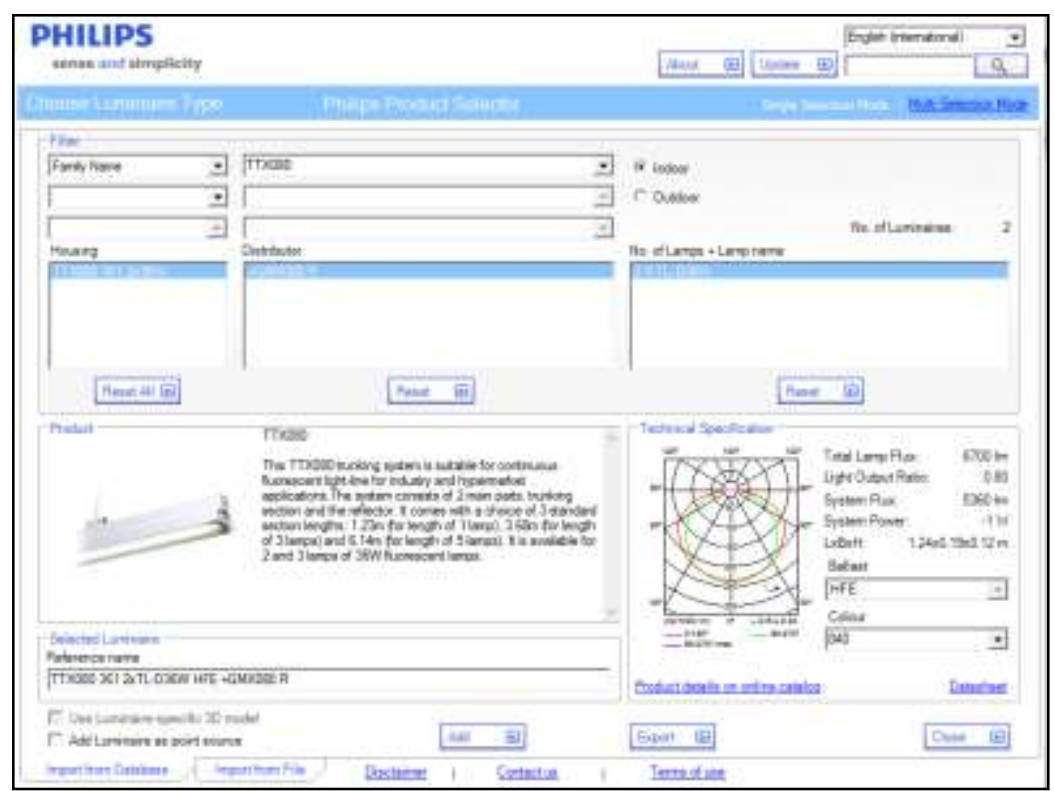

FIGURE 4: Philips TTX080 361 2xTL-D36W HFE +GMX080 R. lamp selection

The Philips TTX080 361 2xTL-D36W HFE + GMX080 $\mathrm{R}$ lamp has a power of $2 \times 36 \mathrm{~W}$, which means the lamp has two TL. This lamp also produces a lumen of 6700 lumens.
After the selection of lights is complete, then proceed with adjusting the number of lights by adjusting the number of lights per row and column and the placement of the height of the lights from the work plane.

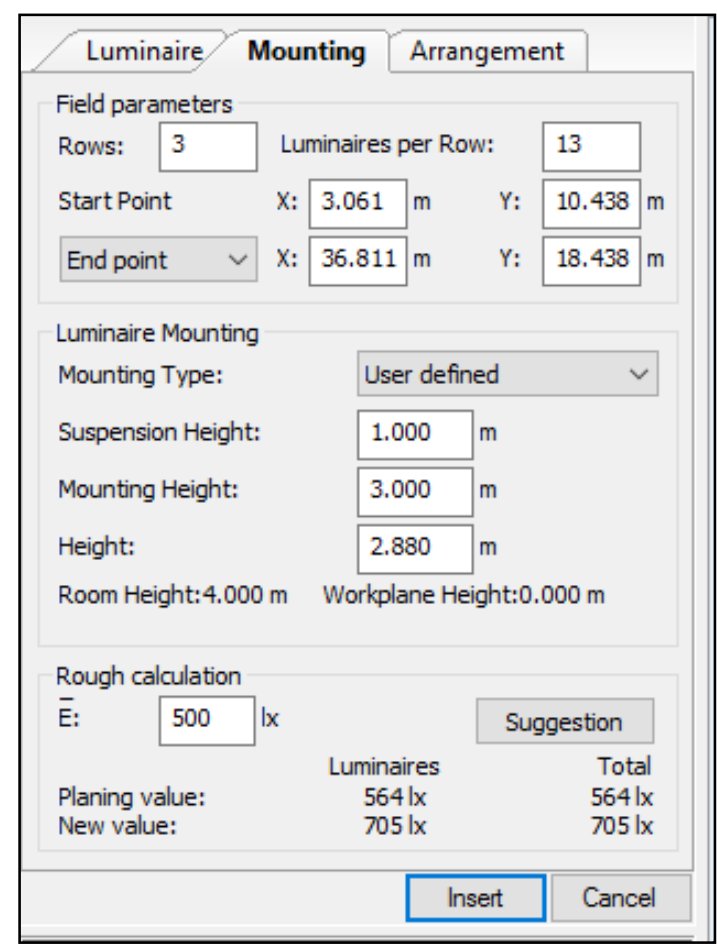

FIGURE 5: Philips TTX080 361 2xTL-D36W HFE +GMX080 R. Lamp Settings

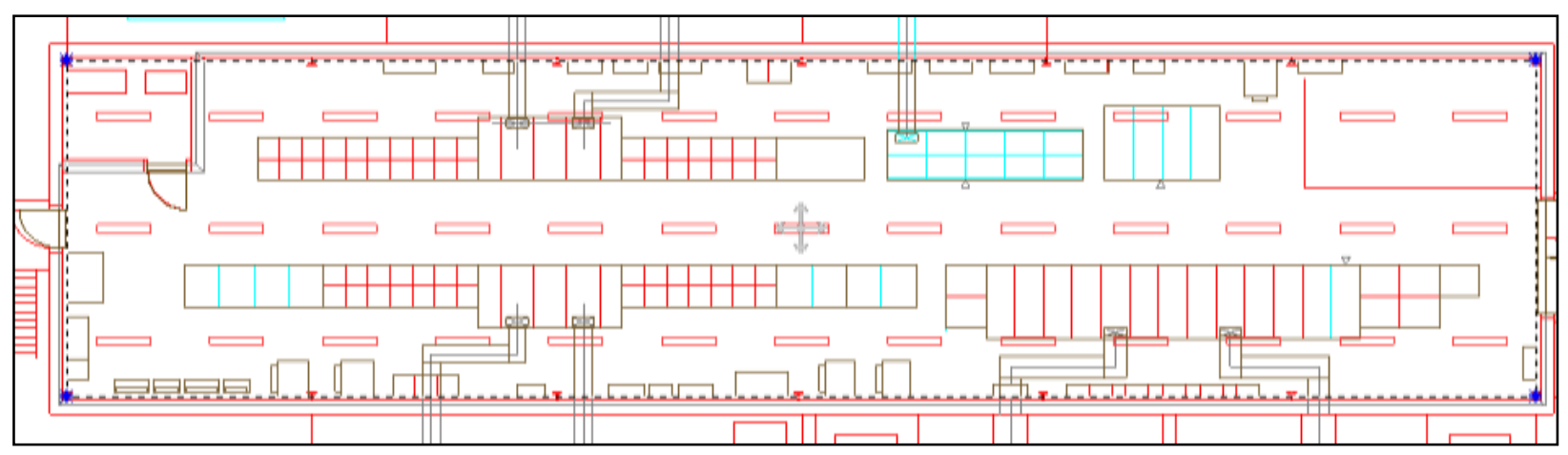

FIGURE 6: Top View Light Settings 
However, in the simulation, the placement of the lamps has not adjusted to other objects in the vicinity, resulting in several lamps colliding or colliding with surrounding objects.

So, this must be corrected by relocating the placement so that there are no more lights that are overlapping or colliding, then the lamp is given a lamp hanger because of the location of the lamp hanging from the ceiling. In addition, lighting arrangements must also pay attention to the aesthetic value (beauty) as well. The following is the display of the lamp settings that have been corrected according to their aesthetic value.

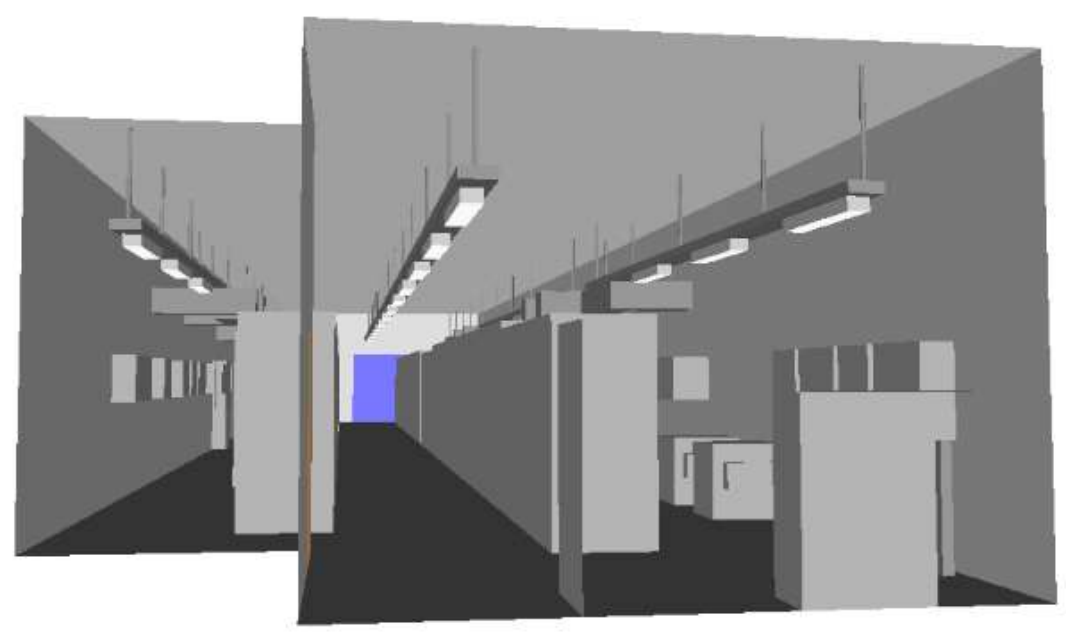

FIGURE 6: Display Room Panel Room

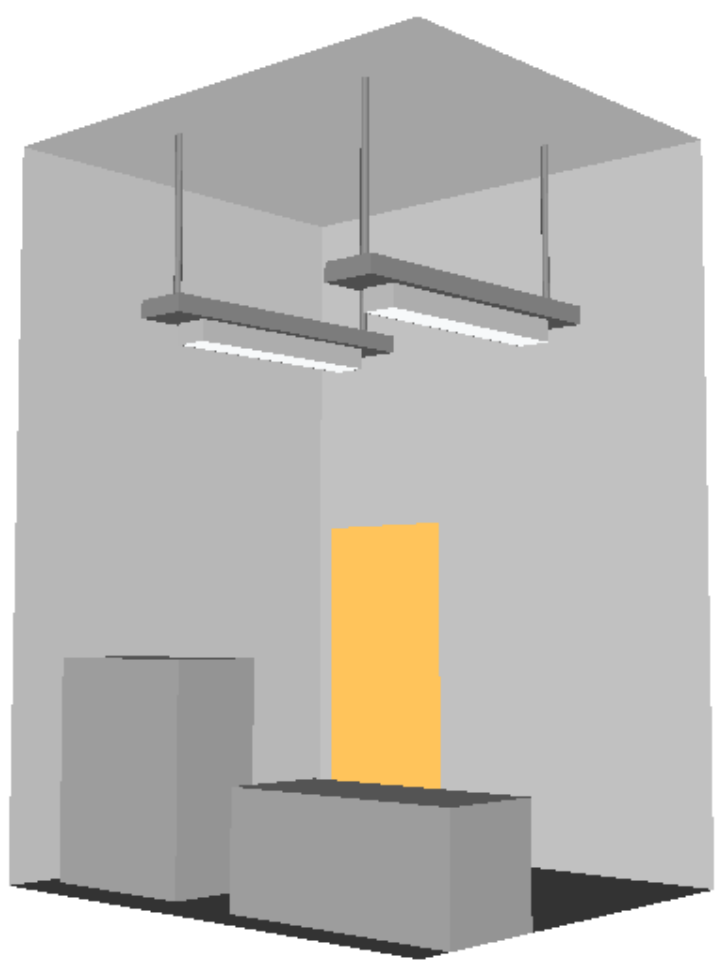

FIGURE 7: Display of Battery Room

Next is to adjust the lighting in normal, emergency, and emergency battery back-up conditions. This is done for security purposes, especially in terms of lighting both in normal conditions and during emergency conditions (emergency). The way to do this is to use the new light scene feature and choose the lights according to the conditions that occur into the control group.

\section{a. Normal Scene}

This condition is a condition where all lighting or lamps work and get a direct supply from PLN. So in this condition all the lights work normally, where the diming value is $100 \%$.

\section{b. Emergency Scene}

In this condition, the supply cut off from PLN. However, in an industry there must be several components that must continue to operate, because 
if these components stop operating there will be damage that can be fatal. The function of the Emergency scene in lighting is to facilitate access for workers to keep control through the available panels or to find a way out. This condition uses a generator as its power source and for lighting only a few lights remain on, depending on the specified lux requirement.

\section{c. Emergency Battery Back-up}

This condition is a very emergency condition, because all supplies from both PLN and generators are not supplied. It can also be related to work accidents or natural accidents (floods, earthquakes, volcanic eruptions, etc.). Therefore, all workers who are in the room must certainly have lighting towards the exit (Escape Plan).
The lights that work are the same lights when an emergency occurs, but the difference is the diming value. Normal lights have a diming of $100 \%$, where the 2 TL lights are lit normally. However, when the battery is back-up, the light only has a diming of 50\%, where only 1 of my TL lights are on. Diming settings can be done by selecting the scene that has been created.

\section{TESTING AND SIMULATION RESULTS}

The test was carried out by running a simulation on the dialux and the results were in the form of a 3D visualization image of each room along with the lighting visualization and data on the average lighting intensity of each room. The way to do this is by selecting the Start Calculation feature, and after that the illumination calculation will be processed.

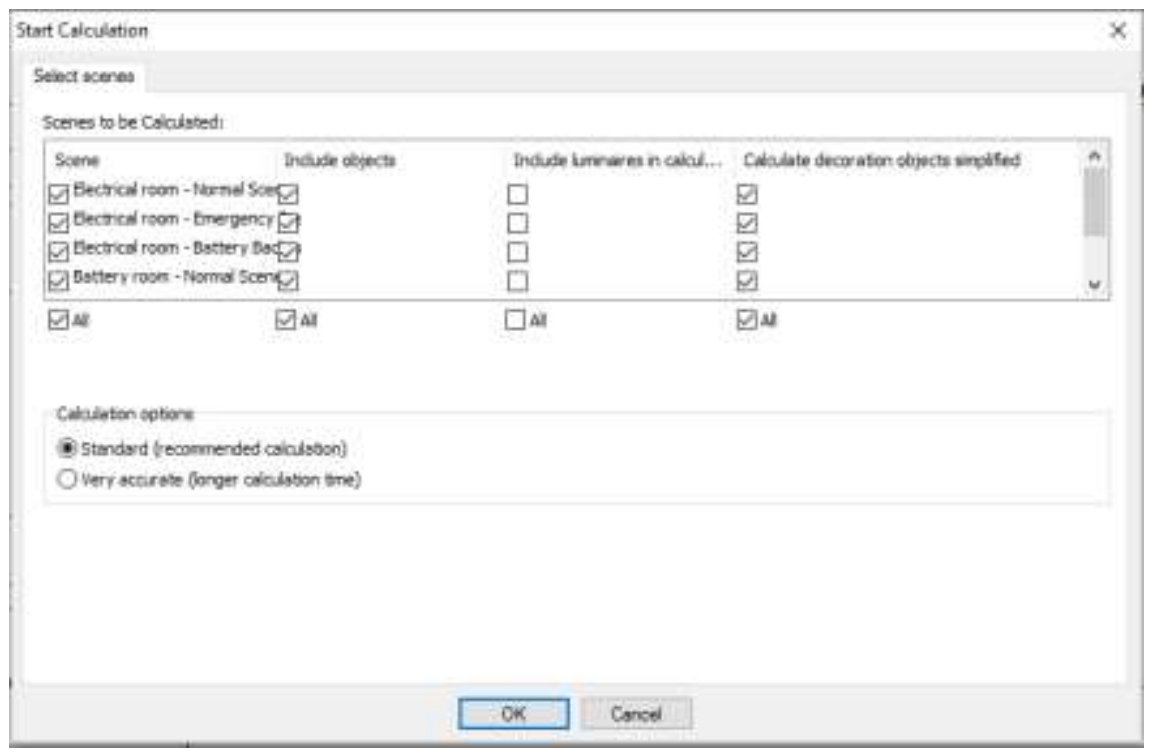

FIGURE 8: Display of the Start Calculation Feature

From the simulation results above, the following data can be obtained:

TABLE 3: Strong Data of Illumination Intensity Simulation Results

\begin{tabular}{|c|c|c|c|c|c|}
\hline Room & Condition & $\begin{array}{l}\text { Number of } \\
\text { lamps }\end{array}$ & $E_{a v}(\operatorname{lux})$ & $E_{\min }(\operatorname{lux})$ & $E_{\max }(\operatorname{lux})$ \\
\hline \multirow{3}{*}{ Panel room } & $\mathrm{N}$ & 37 & 311 & 48 & 448 \\
\hline & $\mathrm{E}$ & 7 & 56 & 2.46 & 192 \\
\hline & $\mathrm{EB}$ & 7 & 28 & 1.23 & 96 \\
\hline \multirow{3}{*}{ Battery room } & $\mathrm{N}$ & 2 & 316 & 37 & 402 \\
\hline & $\mathrm{E}$ & 1 & 158 & 18 & 220 \\
\hline & $\mathrm{EB}$ & 1 & 79 & 9.00 & 110 \\
\hline
\end{tabular}

Based on the simulation data in table 3. The average lighting intensity of each room is obtained as follows:

a. Panel room

Normal

Emergency

: 311 lux (37 lamp)

Emergency Battery Back-up : 31 lux (7 lamp)

b. Battery room

Normal

Emergency

: 316 lux (2 lamp)

: 158 lux (1 l lamp)

Emergency Battery Back-up : 79 lux (1 lamp)
Comparison of Maintenance/Light Loss Factor Variations to Lux

In this comparison, LLF variations of $0.7,0.8,0.9$, and 1 will be used and simulated in the panel room and battery room under normal conditions. The way to do this is to set the light loss factor value in the simulation and run the calculation process on Dialux. After simulating the variation of the Light Loss Factor, the lux calculation results will be obtained as follows: 
TABLE 4: Data Intensity Results with Variation of LLF

\begin{tabular}{|c|c|c|c|c|c|c|}
\hline No. & Room & LLF & Eav (lux) & $E_{\min }(\mathrm{lux})$ & $E_{\max }(\operatorname{lux})$ & $E_{\min } / E_{\max }$ \\
\hline \multirow{4}{*}{1} & \multirow{4}{*}{ Panel room } & 0.7 & 272 & 42 & 392 & 0.106 \\
\hline & & 0.8 & 311 & 48 & 448 & 0.106 \\
\hline & & 0.9 & 349 & 54 & 504 & 0.106 \\
\hline & & 1 & 388 & 60 & 560 & 0.106 \\
\hline \multirow{4}{*}{2} & \multirow{4}{*}{ Battery room } & 0.7 & 276 & 33 & 352 & 0.093 \\
\hline & & 0.8 & 316 & 37 & 402 & 0.093 \\
\hline & & 0.9 & 355 & 42 & 452 & 0.093 \\
\hline & & 1 & 395 & 47 & 502 & 0.093 \\
\hline
\end{tabular}

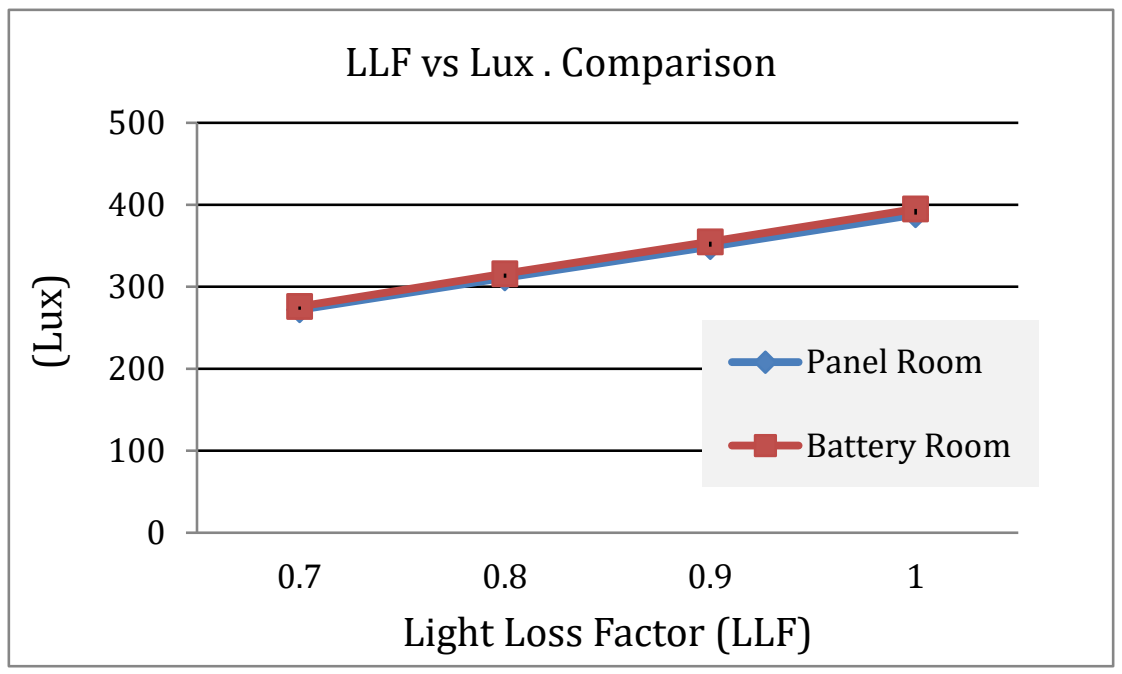

FIGURE 9: LLF Comparison Curve against Lux

In the data table 4 . and figure 13 . it can be seen that changes in the value of the Light Loss Factor (LLF) can affect the resulting lux value. The greater the LLF value, the greater the lux value. So, it can be concluded that the amount of lux is directly proportional to LLF.

\section{Effect of Wall Color on Lux}

Giving color to the walls of the room can actually affect the value of lux.
This is based on the reflection factor which can be affected by the materials and colors used, both on the ceiling (cc), walls (w), and floor ( $\rho f)$. While the value of each reflection factor affects the value of the coefficient of utilization (CU), and will relate to the Lux value.

In this simulation using the panel room and battery room under normal conditions and with an LLF value: 0.8 , the colors to be simulated are the following colors:

\section{(1) Traffic White (9016)}

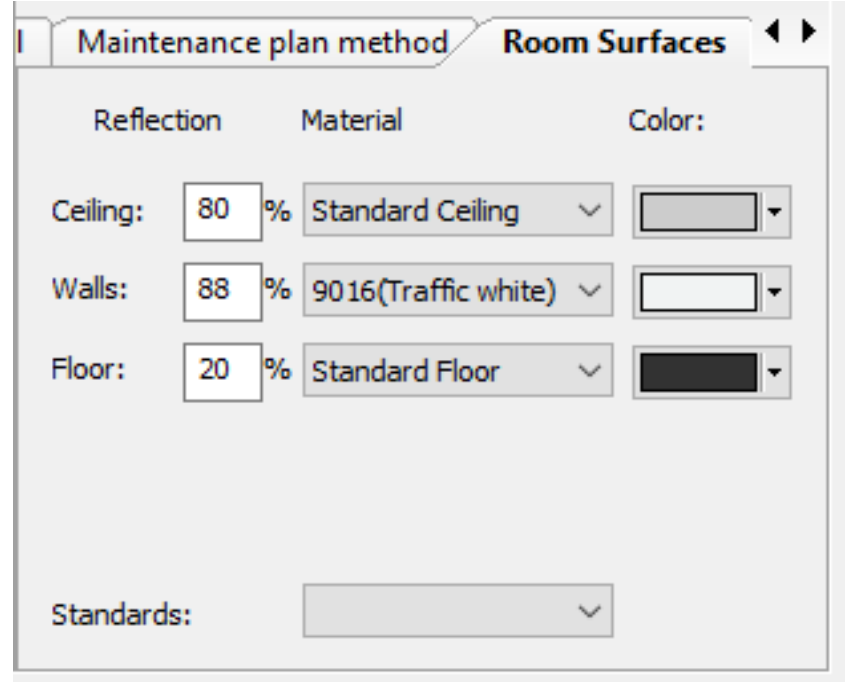

FIGURE 10: Simulation with Traffic White Wall Color (9016) 
From this simulation, the lux calculation is obtained as follows:
a. Panel room :348 lux

b. Battery room : 552 lux

\section{(2) Window Grey (7040)}

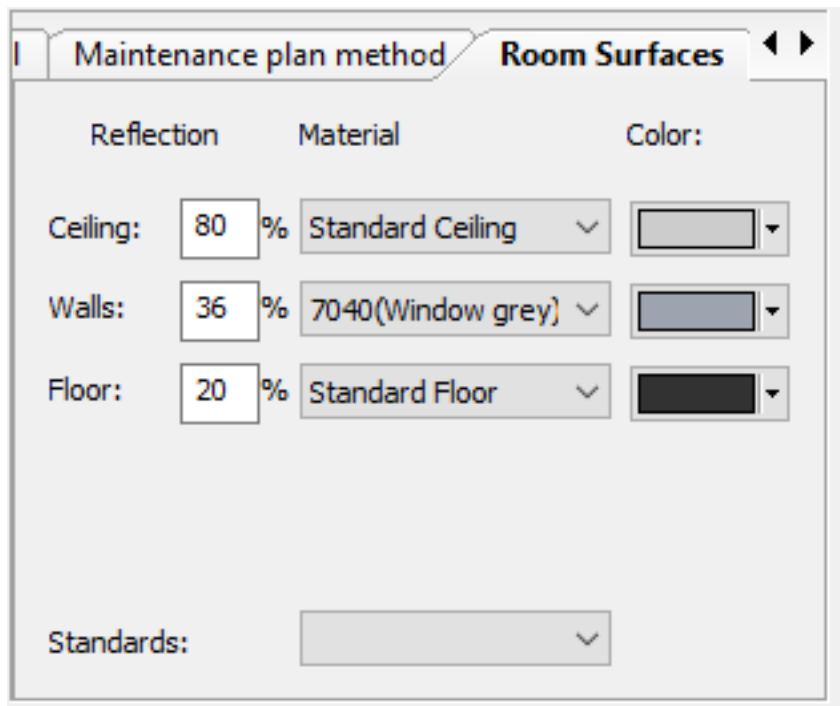

FIGURE 11: Simulation with Window Gray Wall Color (7040)

this simulation, the lux calculation is obtained as follows:
a. Panel room
: 300 lux
b. Battery room : 274 lux

\section{(3) Traffic Black (9017)}

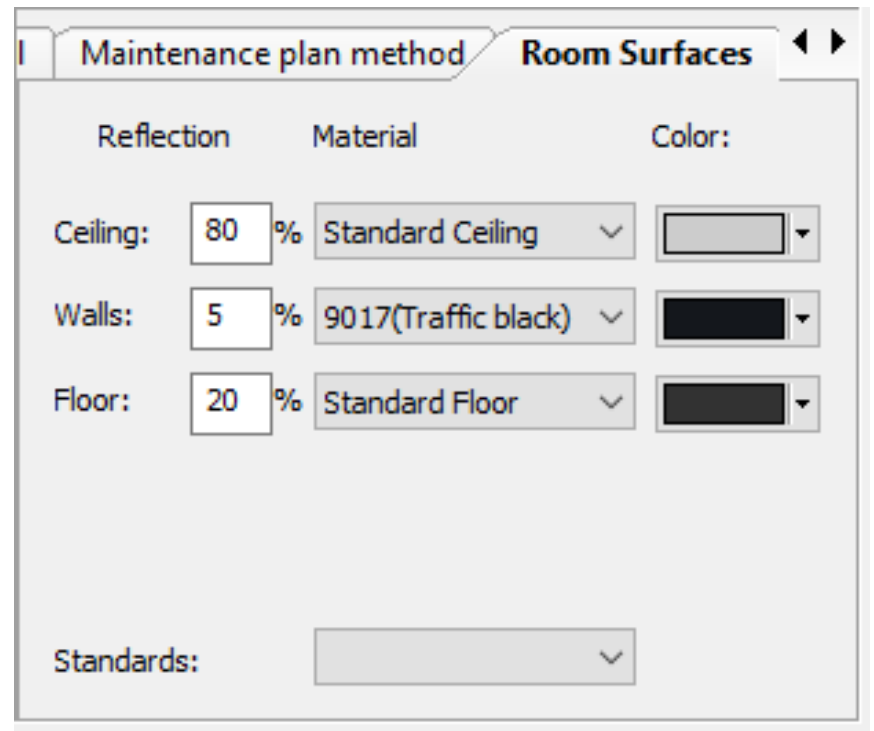

FIGURE 12: Simulation with Traffic Black Wall Color (9017)

From this simulation, the lux calculation is obtained as follows:
a. Panel room : 280 lux
b. Battery room : 215 lux 
From the three-color variations that are simulated eating, table data can be made as follows:

TABLE 5: Comparative Data on Wall Color Variations

\begin{tabular}{|c|c|c|c|}
\hline \multirow{2}{*}{ Room } & Wall Color & Reflection Factor( $\rho$ w) & LightIntensity \\
\hline \multirow{3}{*}{ Panel room } & Traffic White (9016) & $88 \%$ & 348 lux \\
\cline { 2 - 4 } & Window Grey (7040) & $36 \%$ & 300 lux \\
\cline { 2 - 4 } & Traffic Black (9017) & $5 \%$ & 280 lux \\
\hline \multirow{3}{*}{ Battery room } & Traffic White (9016) & $88 \%$ & 552 lux \\
\cline { 2 - 4 } & Window Grey (7040) & $36 \%$ & 274 lux \\
\cline { 2 - 4 } & Traffic Black (9017) & $5 \%$ & 215 lux \\
\hline
\end{tabular}

From the data in table 5 . it can be concluded that color can affect the resulting lux value. This is because lux is influenced by the coefficient of utilization (CU) of the reflection factor on the ceiling 4 . (cc), walls (w), and floor ( $\rho$ ). It can also be concluded 5 . that the lighter the color given to the wall, the greater the reflection factor value, and vice versa, the darker 6 . the color, the smaller the reflection factor. This also applies to giving color to the ceiling and floor.

\section{CONCLUSION}

(1) The lamp used in the simulation is a PHILIPS brand TL lamp with an armature code of TTX 080, namely TTX080 361 2xTL-D36W HFE + GMX080 R lamp.

(2) Based on the simulation of the light loss factor (LLF) variation, the average light intensity is obtained as follows:

a. Panel room

- $0.7 \quad: 272$ lux

- $0.8: 311$ lux

- $0.9: 349$ lux

- $1.0: 388$ lux

b. Battery room

- $0.7 \quad$ : 276 lux

- 0.8 : 316 lux

- 0.9 : 355 lux

- $1.0: 395$ lux

From these data it shows that the greater the LLF value, the greater the lux produced.

(3) Based on the simulation of wall color variations, the average intensity of lighting is obtained as follows:

a. Panel room

- Traffic White (9016) (88\%) : 348 lux

- Window Grey (7040) (36\%) : 300 lux

- Traffic Black (9017) (5\%) : 280 lux

\section{b. Battery room}

- Traffic White (9016) (88\%) : 552 lux

- Window Grey (7040) (36\%): 274 lux

- Traffic Black (9017) (5\%) : 215 lux
The data shows that the lighter the color of the walls and the value of the reflection factor, the greater the lux produced.

The simulation results show that the existing design is in accordance with the Owner's standards.

\section{REFERENCE}

[1] United Nation Environment Programme, Energy Efficiency Guide for Industry in Asia. 2006.

[2] Dial. V.4.8.0.1, DIAL GmbH. Germany, 2010.

[3] Cooper Crouse-Hinds, "Luxicon Pro Training Guide," 2010.

[4] J. HartoSaputro, T. Sukmadi, and Karnoto, "Analisa Penggunaan Lampu LED Pada Penerangan Dalam Rumah," Transmisi, vol. 15, 2103.

[5] Illumination Engineers Society (IES), Illumination Engineers Society (IES) Hand Book.

[6] PT. Rekayasa Industri, "Lighting Illumination Calculation," Jakarta, 2001.

[7] Mcgraw-Hill Book Company, Handbook of Electric Power Calculations.

[8] D. Beckwith, "Solid-State Street Lighting Calculating Light Loss Factors," U.S. Dep. Energy. 